\title{
An Examination of Liking, Love Styles, and Wellness Among Emerging Adults: Implications for Social Wellness and Development
}

\section{W. Matthew Shurts and Jane E. Myers}

\begin{abstract}
Liking, love styles, and wellness were examined in an undergraduate sample $(\mathrm{N}=168)$. Liking and the Mania love style were found to predict $15.8 \%$ of the variance in Total Wellness. In addition, within-group differences in love styles and wellness were found on the basis of gender and ethnicity.
\end{abstract}

Although identity development takes place throughout the life span, an individual's most extensive identity exploration takes place during emerging adulthood (Arnett, 2000), defined as the period from approximately 18 years to 25 years of age. Individuals in this age range do not perceive themselves as adolescents or adults (Arnett, 1998); rather, they identify with multiple roles and have more changes in their worldviews than they have during any other period of their lives (Goldscheider \& Goldscheider, 1994). For emerging adults who choose to attend residential universities, this period of exploration may be intensified as a result of moving from their homes for the first time, living in environments surrounded by many new social, political, religious, and extracurricular ideologies and activities, and adjusting to an array of new social contacts that require effective relationship skills (Arnett, 2000; Lefkowitz, Gillen, Shearer, \& Boone, 2004).

Counselors are in a unique position to help enhance the quality of emerging adults' lives by using preventive and developmental approaches to help undergraduates cope with the challenges of this developmental period. One such approach, wellness counseling, includes an orientation to social relationships as well as other holistic wellness factors. This approach is grounded in

W. Matthew Shurts, Department of Counseling and Educational Leadership, Montclair State University; Jane E. Myers, Department of Counseling and Educational Development, The University of North Carolina at Greensboro. Correspondence concerning this article should be addressed to W. Matthew Shurts, Department of Counseling and Educational Leadership, College of Education and Human Services, Montclair State University, 3230 University Hall, 1 Normal Avenue, Montclair, NJ 07043 (e-mail: shurtsm@mail.montclair.edu).

(C) 2008 by the American Counseling Association. All rights reserved. 
a definition of wellness as "a way of life oriented toward optimal health and well-being, in which body, mind, and spirit are integrated. ... [It is] both the process and goal of optimum human functioning" (Myers \& Sweeney, 2005a, p. 9). Given the developmental importance of intimate relationships during the emerging adulthood years (Chickering \& Reisser, 1993), undergraduates' social wellness and abilities to develop and maintain connections with others are of specific concern. The current study was undertaken to determine how social wellness, operationalized in terms of liking and loving behaviors, is related to overall wellness for undergraduates. A brief review of wellness research with undergraduate populations and studies on liking and loving is provided as a context for our research questions and hypotheses.

\section{WELLNESS}

The Indivisible Self model of wellness (IS-Wel; Myers \& Sweeney, 2005a) is one of a variety of models (e.g., Hettler, 1984) proposed to promote understanding of holistic wellness factors. This model is unique in both its foundation in counseling theory and its development through research. The IS-Wel emerged from factor analytic studies of a large database of both undergraduate and nonstudent adult populations of all ages (Hattie, Myers, \& Sweeney, 2004). Using structural equation modeling, the IS-Wel was defined as having a nested factor structure with a single higher order wellness factor (Total Wellness), 5 second-order factors, and 17 discrete third-order factors grouped within the second-order factor structure. As shown in Figure 1, the second-order factors are Creative Self (attributes contributing to individuals' unique place in the world), Coping Self (elements that regulate responses to life events), Social Self (social support through friendships and intimate relationships), Essential Self (essential meaning-making processes in relation to life, self, and others), and Physical Self (physiological processes that affect development and functioning). The strength of the Total Wellness factor underscores the indivisibility of the self, the interrelationship of all wellness components, and the fact that change in one area of wellness contributes to changes in other areas.

The IS-Wel model has been used in numerous studies of diverse persons across the life span, and multiple studies have examined both gender and ethnic differences in wellness (see Myers \& Sweeney, 2005a). Osborn (2005) reviewed the empirical literature on wellness of undergraduates, noting inconsistencies among findings across studies. For example, Myers and Mobley (2004) found that scores for undergraduates were lower than those for nonstudent adults in multiple wellness areas, including the Social Self (Friendship and Love). Yet, the Social Self was the strongest wellness factor reported by 190 White, undergraduate women at a southeastern university (Sinclair \& Myers, 2004), and the highest wellness score among 203 African American male junior and senior college students (Spurgeon \& Myers, in press). 


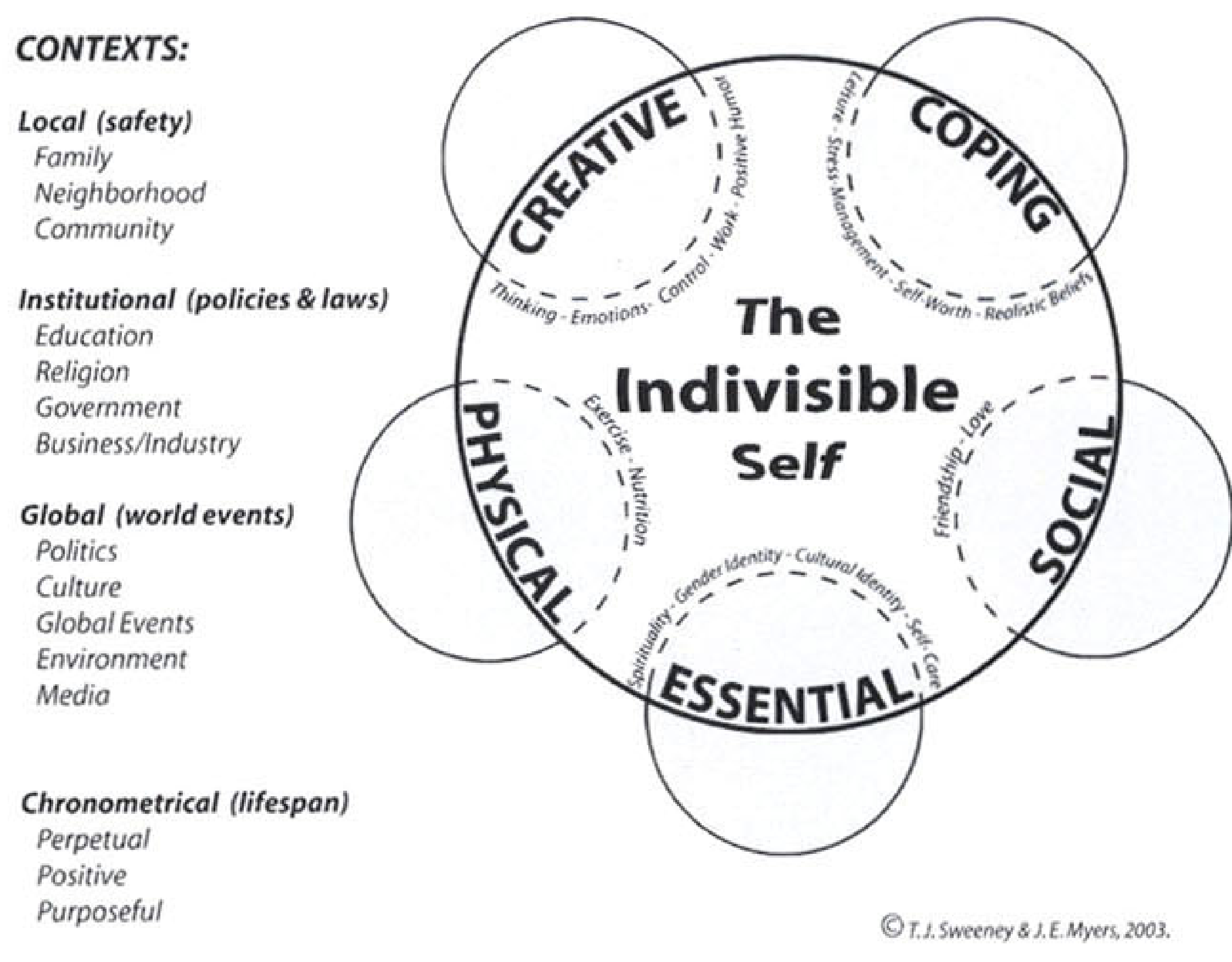

FIGURE 1

\section{The Indivisible Self: An Evidence-Based Model of Wellness}

Note . Creative $=$ Creative Self; Coping $=$ Coping Self; Social $=$ Social Self; Essential $=$ Essential Self; Physical $=$ Physical Self. From The Indivisible Self: An Evidence-Based Model of Wellness, by T. J. Sweeney and J. E. Myers, 2003, Greensboro, NC: Author. Copyright 2003 by T. J. Sweeney and J. E. Myers. Reprinted with permission.

Regarding gender differences, Myers and Mobley (2004) found that scores for women were higher than those for men on the Essential Self and Love, and scores for men were higher than those for women on the Coping Self and Physical Self. However, Myers and Bechtel (2004) found dissimilar gender differences among undergraduate military cadets, with scores for men higher than those for women on Stress Management and Self-Worth only and no wellness areas in which scores for women were higher than those for men. In Enochs's (2001) study of 511 traditional age freshmen, no gender differences in wellness were found.

Few studies have explored wellness differences across ethnic groups. Dixon Rayle and Myers (2004) compared minority and nonminority adolescents on several variables and found no statistically significant differences in wellness factors, possibly because all ethnic minorities were grouped into one data set. In contrast, Myers and Mobley (2004) found numerous differences in wellness between Caucasian and minority students, with scores for Caucasian students higher on the Social Self and Physical Self and scores for minority students higher on Realistic Beliefs and Cultural Identity. Shurts (2004) found that scores for 
Caucasian undergraduates were higher than those for African American students on the Physical Self, whereas scores for African American undergraduates were higher than those for Caucasian students on the Coping Self and Essential Self (all differences with medium to large effects).

As Osborn (2005) noted, the body of comparative studies examining gender and ethnic differences among undergraduates has yielded equivocal results. She concluded that social expressions of wellness stand out as important in this population but are in need of further study because of conflicting results in the literature.

\section{SOCIAL WELLNESS, LIKING, AND LOVING AMONG COLLEGE STUDENTS}

Shifren, Furnham, and Bauserman (2003) observed that undergraduates constitute a population facing numerous risks and undergoing many developmental changes. Although holistic wellness is a salient concern for these emerging adults (Osborn, 2005), social wellness is especially significant given that learning how to establish and maintain healthy, intimate relationships with friends and romantic partners is a primary developmental task (Chickering \& Reisser, 1993). Undergraduates consistently have self-reported high levels of social wellness (e.g., Myers \& Mobley, 2004), and friendships are among the strongest predictors of their psychological well-being (Hermon \& Hazler, 1999); however, relationship problems are among the primary presenting issues in university counseling centers for both men and women (Sandler, 1998), including friendships that involve liking and more intimate relationships that involve loving.

Myers and Sweeney (2005a) noted that liking and loving occur on a continuum and are often difficult to separate and to define. These authors defined liking as a platonic, interpersonal relationship that does not involve a marital, sexual, or familial commitment and loving as a relationship that includes feelings of intense attraction, passion, and sexual intimacy. Studies of friendship wellness among undergraduates have provided conflicting information, given that some findings suggest that gender differences exist in friendship wellness (e.g., Myers \& Bechtel, 2004) whereas other studies find no such differences (e.g., Enochs, 2001).

As is true of liking, loving is difficult to define, explain, and measure (Myers \& Shurts, 2002). Lee (1973) identified six love styles as dynamic preferences that occur concurrently, develop and change over time (short and long term; Bierhoff \& Schmohr, 2004), and are satisfied in and through different relationships. Three love styles are labeled as primary: Eros (romantic or passionate love), Ludus (game-playing love), and Storge (friendship love). These primary styles can combine to form three secondary love styles: Mania (Ludus/Eros; obsessive love), Pragma (Storge/Ludus; practical, pragmatic love), and Agape (Eros/Storge, altruistic love).

Because of conflicting results among the studies of love styles that appear in the literature, the dynamics of undergraduates' love styles can be difficult to fully 
understand, especially when considering differences in gender and ethnicity. For example, although scores for men are consistently higher than those for women on the Ludus love style (Lin \& Huddleston-Casas, 2005), scores for women are usually higher than those for men on the Storge, Mania, and Pragma love styles (Neto \& Pinto, 2003). No clear patterns emerge for the Agape love style (Sprecher \& Toro-Morn, 2002). In contrast, female undergraduates in Myers and Mobley's (2004) study reported significantly higher Love wellness than did male undergraduates. The large effect size for this difference cannot be explained in relation to love styles, which are not a part of the IS-Wel model. Inconsistent results suggest a need for further study of gender differences in love styles. Similarly, few studies exploring ethnic differences in love styles have been conducted. Hendrick and Hendrick (1986) compared ethnic groups and found no differences on the Ludus and Mania love styles, but noted that "Black students were least agapic, although not all mean comparisons were significant due to the small number of Black [students]" (p. 397). The lack of love style differences is somewhat surprising, given the vast literature detailing cultural differences in individuals' understanding of their relationships with others (e.g., Gushue \& Constantine, 2003). These differences could influence primary love styles within groups and the approach that counselors would subsequently take in working with relationship issues; however, few studies have examined how these potential differences might affect romantic relationships (Guarascio, 2005). Consistent patterns of love styles based on ethnicity have not been identified. Moreover, most studies are dated and may not generalize to students in the new millennium.

In summary, although multiple studies have suggested that friendship and intimacy patterns differ between women and men (DeLucia-Waack, Gerrity, Taub, \& Baldo, 2001), research on gender differences in undergraduates' social wellness has yielded equivocal findings. Myers and Mobley (2004) concluded that "undergraduate students are challenged relative to the establishment of friendships" (p. 46) and that "the dynamics of relationship issues for undergraduates merit further exploration" (p. 47). To date, no empirical studies have been conducted that examine the IS-WEL factors Friendship and Love, aspects of social wellness, in relation to other holistic wellness factors among emerging adults. An examination of these relationships could provide evidence on which to base counseling interventions to enhance relationships skills and relationship health in this at-risk population.

\section{PURPOSE OF STUDY AND HYPOTHESES}

The present study was undertaken to examine the relationships between liking, loving, and holistic wellness among emerging adult college students. Because of prior equivocal findings, we chose to both replicate aspects of existing studies and conduct new analyses to determine the predictive power of the variables on 
Total Wellness and identify potential within-group differences. Research questions were designed to determine relationships among the variables; examine the extent to which wellness could be predicted by a combination of liking and love styles; and compare liking, loving, and wellness across gender, ethnic group, and age. Six hypotheses were tested:

Hypothesis 1: Negative love styles will be least endorsed.

Hypothesis 2: Significant positive relationships will exist between liking, positive love styles, and wellness, whereas negative correlations will exist between negative love styles and wellness.

Hypothesis 3: Liking and love styles will predict a significant portion of the variance in wellness.

Hypothesis 4: Gender differences in liking and love styles will be evident, with scores for women higher than those for men on liking and the Storge, Mania, and Pragma love styles and scores for men higher than those for women on the Ludus love style.

Hypothesis 5: Ethnic group differences will exist, with scores for Caucasian participants higher than those for African American participants on the Agape love style and Total Wellness.

Hypothesis 6: No age differences will exist between the three variables.

\section{METHOD}

Following institutional review board approval, convenience samples of volunteer undergraduate participants $(N=168)$ were recruited from two schools: a small university in the Midwest $(n=18)$ and a mid-sized university in the Southeast ( $n$ $=150$ ). Students completed the instruments in the same sequence during class in their human development and career and life planning courses. Participants received their scores, profiles, and a group interpretation with the opportunity for questions and follow-up referrals for counseling.

\section{Participants}

Almost $75.0 \%$ of participants were women. Of the 168 participants, $47.0 \%$ identified as Caucasian, 24.4\% as African American, $10.1 \%$ as Hispanic, and $11.4 \%$ as other; $7.1 \%$ did not report ethnicity. Participants' ages ranged from 18 years to 56 years, with a mean of $25.12(S D=7.76, M d n=23)$. Demographic characteristics of the two samples were comparable for gender and age.

\section{Instruments}

Liking. Rubin (1970) defined liking as a platonic, interpersonal relationship that does not involve a marital, sexual, or familial commitment. The Rubin Liking Scale (RLS; Rubin, 1970) used a 9-point Likert-type rating scale; modifications to this scale by Nava and Bailey (1991) resulted in a 5-point scale, 
which was used in the present study. When completing the RLS, respondents are instructed to focus on a close, same-sex friend and respond to 13 items that are statements about that friend (e.g., "___ is one of the most likable people I know"). Respondents rate each item using a 5-point Likert-type scale ranging from 1 (not at all trueldisagree completely) to 5 (definitely truelagree completely). Responses are summed to yield a total score (RLS) that ranges from 13 to 65. Higher scores indicate greater interpersonal attraction or liking. The only published norms for the RLS were based on an earlier and somewhat different version and are not appropriate for comparison with the current data. The RLS was developed to establish construct and discriminate validity of scores for the Rubin Love Scale (Rubin, 1970), a measure of "romantic love." Because scores of the RLS correlated only moderately with those of the Rubin Love Scale ( $r$ $=.39$ for women; $r=.60$ for men), Rubin concluded that the RLS measures a separate construct. He reported alpha coefficients of .81 to .83 in separate studies; the alpha for the present study was .87 .

Loving. The Love Attitudes Scale (LAS; Hendrick, Hendrick, \& Dicke, 1998), a 24-item instrument comprising six 4-item subscales, was designed to measure each of Lee's (1973) six love styles. In the present study, reverse scoring was used for the response scale. Items are statements concerning a current partner and relationship or ideal relationship (e.g., "I feel that my partner and I were meant for each other"). Respondents rate each item using a 5-point Likert-type scale ranging from 1 (strongly disagree) to 5 (strongly agree). Subscale scores range from 4 to 20 , with higher scores indicating greater feelings of love. Norms have not been published. The LAS emerged in Myers and Shurts (2002) review as one of the strongest currently available psychometric tools for conducting research involving love. Cronbach's alphas are in the $.70 \mathrm{~s}$ and $.80 \mathrm{~s}$ for all subscales (Hendrick et al., 1998). A factor analysis of 847 undergraduates ( $64 \%$ female students) supported the six proposed love styles (Hendrick \& Hendrick, 1989). In the present study, alphas for the LAS subscales ranged from .71 (Pragma) to .86 (Storge), with the exception of Ludus (.57).

Wellness. The Five Factor Wellness Inventory (5F-Wel; Myers \& Sweeney, 2005 b) is a 73-item instrument developed to assess each of the factors in the IS-Wel. Each item is a statement about healthy lifestyles (e.g., "I am an active person"). Respondents rate each item using a 4-point Likert-type scale ranging from 1 (strongly disagree) to 4 (strongly agree). Scale scores are sums of item responses, linearly transformed to create scales ranging from 25 to 100 ; higher scores indicate higher wellness. The 5F-Wel provides scores for Total Wellness, 5 second-order factors, and 17 third-order factors in the IS-Wel model. This study examined the Total Wellness factor, the 5 second-order factors, and 2 third-order factors (Friendship and Love). Myers and Sweeney (2005a) reported alpha coefficients ranging from .91 to .94 for the 5 second-order factors. The alphas in the present study ranged from .79 (Social Self and Essential Self) to .84 (Creative Self and Coping Self); the alpha for Total Wellness was .83. 


\section{Data Analyses}

Descriptive statistics and reliabilities were computed for all instruments and scales. Pearson product-moment correlations, regression analyses, and multivariate analyses of variance (MANOVAs) were computed to test the hypotheses. An alpha of .05 was used to determine statistical significance for the correlations, and a Bonferroni correction was used to set the alpha at .01 for the MANOVAs to reduce the likelihood of Type I errors. Because of the low proportion of minority students in the total sample, only two ethnic groups were examined (Caucasian students and African American students). Two age groups were examined: traditional (students ages 18-25 years) and nontraditional (students ages 26 years and older). Norm scores were not available for the RLS and LAS; however, scores for the current sample were compared with existing norms for the 5F-Wel.

\section{RESULTS}

A review of descriptive statistics for each instrument revealed a wide range of scores for the RLS and the 5F-Wel Friendship scale, with students at both ends of the possible continua. The mean score for the RLS was in the higher score range. The highest mean wellness scores were reported for the Social Self $(M=$ 88.06, $S D=10.11)$, especially the Love scale $(M=90.8, S D=11.8)$.

Descriptive statistics revealed that the two negative love styles-Ludus ( $M$ $=8.1, S D=3.3)$ and Mania $(M=10.4, S D=3.7)$-were the least endorsed (i.e., had the lowest means). The most endorsed love style was Eros $(M=16.4$, $S D=3.2$ ). Thus, Hypothesis 1 was supported.

Pearson product-moment correlations computed between the scales revealed that correlations between the RLS and all wellness factors were positive and statistically significant, with the exception of the Coping Self and Physical Self (see Table 1). The $R^{2}$ results for these correlations are only $11 \%$ at best when examining shared variance, suggesting low to moderate levels of clinical or practical significance. As hypothesized, a number of positive relationships existed between the positive love styles and wellness factors (as indicated by scores on the respective scales/subscales). The Eros subscale correlated significantly and positively with Total Wellness $(r=.17)$, the Coping Self $(r=.21)$ and Social Self $(r=.26)$ scales, and both third-order factors (Friendship, $r=.26$; Love, $r=.19$ ). The Pragma subscale correlated positively with the Essential Self $(r=.21)$ scale. The Agape subscale correlated positively with the Social Self and the Love scales $(r=.19$ and .20 , respectively). Unexpectedly, no positive correlations were found between the Storge subscale and any of the 5-F WEL scales. Contrary to the hypothesis, no significant negative correlations existed between the Ludus subscale (negative love style) and any wellness factor. However, the Mania subscale (negative love style) did correlate significantly and negatively with the Coping Self $(r=-.25)$ and Essential Self $(r=-.23)$ scales and Total Wellness $(r=-.26)$. These findings provided partial support for Hypothesis 2 . 
TABLE 1

Pearson Product-Moment Correlation Coefficients Between the Rubin Liking Scale (RLS), the Love Attitudes Scale (LAS)

Subscales, and the Five Factor Wellness Inventory (5F-Wel)

\begin{tabular}{|c|c|c|c|c|c|c|c|}
\hline \multirow[b]{2}{*}{ Scale } & \multicolumn{7}{|c|}{ RLS and LAS Subscales } \\
\hline & 1 & 2 & 3 & 4 & 5 & 6 & 7 \\
\hline 1. RLS & - & & & & & & \\
\hline \multicolumn{8}{|l|}{ LAS } \\
\hline 2. Eros & $.21^{* *}$ & - & & & & & \\
\hline 3. Ludus & $-.19^{* *}$ & $-.33^{* * *}$ & - & & & & \\
\hline 4. Storge & .05 & .11 & $-.20^{*}$ & - & & & \\
\hline 5. Mania & -.04 & .01 & $.23^{* *}$ & -.11 & - & & \\
\hline 6. Pragma & .12 & .00 & .04 & .14 & -.01 & - & \\
\hline 7. Agape & .14 & $.22^{* *}$ & -.12 & -.07 & $.34 \cdots$ & $-.17^{*}$ & - \\
\hline \multicolumn{8}{|l|}{$5 \mathrm{~F}-\mathrm{Wel}$} \\
\hline Creative & $.33 \cdots$ & .07 & -.06 & .05 & -.18 & .01 & .01 \\
\hline Coping & .11 & $.21^{* * *}$ & -.09 & .18 & $-.25^{* * *}$ & -.02 & -.02 \\
\hline Social & $.38 \cdots$ & $.26^{\star \star \star}$ & -.08 & -.01 & -.08 & -.07 & $.19^{*}$ \\
\hline Friendship & $.36 * *$ & $.26^{\star \star *}$ & -.06 & $<.01$ & -.04 & -.02 & .14 \\
\hline Love & $.30 \cdots$ & $.19^{*}$ & -.09 & -.02 & -.11 & -.12 & $.20^{* *}$ \\
\hline Essential & $.31 \cdots$ & .05 & -.06 & .17 & $-.23^{* *}$ & $.21^{* *}$ & .04 \\
\hline Physical & .07 & .05 & .04 & .14 & -.10 & -.08 & $<.01$ \\
\hline Total Wellness & $.32 \cdots$ & $.17^{*}$ & -.08 & .14 & $-.26 * * *$ & .02 & $<.01$ \\
\hline
\end{tabular}

Note . Creative $=$ Creative Self; Coping $=$ Coping Self; Social $=$ Social Self; Essential $=$ Es sential Self; Physical $=$ Physical Self.

${ }^{*} p<.05 .{ }^{* *} p<.01 .{ }^{* * *} p<.001$.

Scatterplot representations and correlations were examined to determine which variables to include in the regression analyses. Only the RLS $(r=.32, p<.001)$ and the Eros $(r=.17, p<.05)$ and Mania $(r=-.26, p<.001)$ subscales showed evidence of possible relationships with Total Wellness. A stepwise linear regression model including only these variables was estimated with the probability of $F$ for entry set at the .05 significance level and the probability of $F$ for removal set at the .10 level. Using these criteria, only the RLS and the Mania subscale entered the regression equation, resulting in the following estimation equations:

$$
\begin{aligned}
& \text { Total Wellness }=61.968+(.323)(\text { RLS }) \text {; and } \\
& \text { Total Wellness }=67.322+(.313)(\text { RLS })+(-.253)(\text { Mania }) \text {. }
\end{aligned}
$$

The two variables together explained $15.8 \%$ of the observed variability in Total Wellness scores. The correlation between the observed Total Wellness scores and the predicted values on the basis of the second equation was $r=.41$. Two additional stepwise linear regression models were estimated to ascertain whether the variance of the Friendship and Love scales was more strongly predicted by scores on the RLS and/or the Eros and Mania subscales than by Total Wellness. These analyses yielded results similar to the equations just reported, providing partial support for Hypothesis 3. 
Table 2 shows the results of hypothesis testing to determine possible withingroup differences on the basis of gender, ethnicity, and age (Hypotheses 4, 5 , and 6). No differences existed in scores on the RLS for any of the demographic variables. Only three gender differences were identified, with scores for men higher than those for women on the Agape subscale $\left(F=11.50, p<.001, \eta^{2}=.066\right)$ and the Coping Self and Physical Self scales $\left(F=12.06, p<.001, \eta^{2}=.069 ; F\right.$ $=11.59, p<.001, \eta^{2}=.066$, respectively). MANOVAs computed for ethnicity resulted in three significant differences between Caucasian and African American students in scores on the LAS subscales. As hypothesized, scores for Caucasian students were higher on the Mania $\left(F=12.29, p<.001, \eta^{2}=.095\right)$ and Agape $(F$ $\left.=14.84, p=.000, \eta^{2}=.113\right)$ subscales, and scores for African American students were higher on the Pragma subscale $\left(F=6.73, p<.010, \eta^{2}=.054\right)$. Regarding the wellness differences between Caucasian and African American students, Caucasian students reported higher Physical Self wellness $\left(F=12.89, p<.001, \eta^{2}=.099\right)$, whereas African American students reported higher Essential Self wellness $(F=$ $\left.14.76, p<.001, \eta^{2}=.112\right)$. Effect sizes for these differences were moderate. No age differences were found on any scales.

Scores for the current participants were compared with those for a database norm group composed of 1,567 undergraduates used in Myers and Mobley's (2004) study. Scores for the current participants were higher on both the Social Self and the Essential Self $(t=4.57, d f=1733, p<.001 ; t=10.12, d f=1733$, $p<.001$, respectively) and lower on the Physical Self $(t=-3.84, d f=1733, p$ $<.001)$; no differences were found for the Creative Self, Coping Self, or Total Wellness. Follow-up analyses of the third-order factor structure revealed that the differences found on the Social Self were due to higher scores on the Love scale; no differences existed on the Friendship scale. Further examination of RLS and LAS scores was not possible because of the absence of relevant norm group scores.

\section{DISCUSSION}

Relationship factors for emerging adult college students were examined in relation to holistic wellness and five wellness factors, replicating aspects of previous studies and adding new comparative analyses. As was true in earlier studies (e.g., Myers \& Mobley, 2004), undergraduates reported high Social Self wellness. They also were extremely variable on measures of liking (the RLS) and friendship (the 5F-Wel Friendship scale) and endorsed positive love styles more so than negative styles. As expected, positive correlations were found between positive love styles and wellness and negative correlations were found between negative love styles and wellness. Scores on the RLS and the Mania subscale (through an inverse relationship) contributed $15.8 \%$ of the variance in Total Wellness. Several within-group differences were found on the basis of gender (male vs. female students) and ethnicity (Caucasian vs. African American students), but 
TABLE 2

Results of $t$ Tests Comparing Participants With Norm Groups and Multivariate Analyses of Variance for Gender, Ethnicity (Caucasian vs. African American), and Age (Traditional vs. Nontraditional)

\begin{tabular}{|c|c|c|c|c|c|c|c|c|c|c|c|}
\hline \multirow[b]{3}{*}{ Scale } & \multirow{2}{*}{\multicolumn{3}{|c|}{$t$ Tests With Norm Groups }} & \multicolumn{8}{|c|}{ Within-Group Multivariate Analyses of Variance } \\
\hline & & & & \multicolumn{3}{|c|}{ Gender } & \multicolumn{3}{|c|}{ Ethnicity } & \multicolumn{2}{|c|}{ Age } \\
\hline & $t$ & $d f$ & $p$ & $F$ & $p$ & $\eta^{2}$ & $F$ & $p$ & $\eta^{2}$ & $F$ & $p$ \\
\hline Rubin Liking Scale & & & & 2.32 & .130 & & 0.10 & .757 & & 0.02 & .887 \\
\hline \multicolumn{12}{|l|}{ Love Attitudes Scale } \\
\hline Eros & & & & 0.02 & .902 & & 0.90 & .344 & & 6.32 & .013 \\
\hline Ludus & & & & 0.02 & .899 & & 0.65 & .422 & & 0.22 & .638 \\
\hline Storge & & & & 0.13 & .722 & & 0.31 & .582 & & 1.12 & .291 \\
\hline Mania & & & & 0.64 & .426 & & 12.29 & $.001^{\star * \star}$ & $.095^{a}$ & 5.71 & .018 \\
\hline Pragma & & & & 4.41 & .037 & & 6.73 & $.010^{\star *}$ & $.054^{\mathrm{b}}$ & 2.79 & .097 \\
\hline Agape & & & & 11.50 & $.001^{\star \star \star}$ & $.066^{c}$ & 14.84 & $.000^{\star \star \star}$ & $.113^{a}$ & 1.32 & .253 \\
\hline \multicolumn{12}{|l|}{$5 F-W e l$} \\
\hline Creative & 0.87 & 1733 & .384 & 1.39 & .240 & & 1.84 & .185 & & 2.31 & .131 \\
\hline Coping & 0.98 & 1733 & .327 & 12.06 & $.001^{* * *}$ & $.069^{c}$ & 0.10 & .750 & & 1.92 & .167 \\
\hline Social & 4.57 & 1733 & $<.001^{\star * *}$ & 0.78 & .378 & & 0.57 & .452 & & 1.89 & .172 \\
\hline Friendship & 1.77 & 1733 & .077 & 1.89 & .171 & & 0.38 & .540 & & 4.54 & .035 \\
\hline Love & 6.27 & 1733 & $<.001^{\star \star \star *}$ & 0.03 & .858 & & 0.45 & .506 & & 0.07 & .793 \\
\hline Essential & 10.12 & 1733 & $<.001^{\star \star \star}$ & 4.26 & .041 & & 14.76 & $.001^{* \star *}$ & $.112^{\mathrm{b}}$ & 1.76 & .187 \\
\hline Physical & -3.84 & 1733 & $<.001^{\star * *}$ & 11.59 & $.001^{* * *}$ & $.066^{c}$ & 12.89 & $.001^{* * * *}$ & $.099^{a}$ & 0.00 & .974 \\
\hline Total Wellness & -1.28 & 1733 & .201 & 3.18 & .076 & & 0.25 & .618 & & 2.60 & .109 \\
\hline
\end{tabular}

Note. To interpret $\eta^{2}$ (effect size), . $010=$ small; $.060=$ medium; .150 =large (Cohen, 1988). For Age, $\eta^{2}$ was omitted because it is not necessary to calculate effect size for these values. $5 \mathrm{~F}-\mathrm{Wel}=$ Five Factor Wellness Inventory; Creative = Creative Self; Coping $=$ Coping Self; Social $=$ Social Self; Essential $=$ Essential Self; Physical $=$ Physical Self.

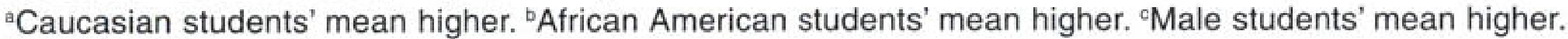

${ }^{\star \star} p<.01 .{ }^{* \star *} p<.001$. 
not age. These results both support important aspects of earlier studies and provide new information relative to undergraduate relationships.

\section{Relationships Among Liking, Love Styles, and Wellness}

The expected positive correlations between wellness factors and liking support both our initial hypothesis and earlier findings that social support and wellness are related. Similarly, positive correlations between positive love styles and Social Self wellness were expected and consistent both with theory and prior research. In contrast, on the basis of Lee's (1973) theory, we expected to find positive correlations between Love wellness and all four positive love styles, not just Eros and Agape. The "ideal" of romantic love among the college population in which the partner's wishes are put first may be more closely tied to Love wellness than to a more platonic, rationalistic approach (i.e., the Storge and Pragma love styles). These findings merit further study, especially in light of the unexpected finding that, as indicated by scores on the respective subscales, the Ludus love style was not correlated negatively with any of the wellness factors and the Mania love style was negatively related to only two second-order factors and Total Wellness. The lack of a clear pattern in the results suggests a more complex relationship between love styles and wellness than originally hypothesized. Although it seems intuitively correct that healthy love relationships are related to greater well-being and vice versa, the current findings do not support this seemingly simplistic assumption.

Contrary to expectations, the Mania subscale scores were not significantly negatively related to scores on either Friendship or Love wellness. Few respondents in the current study endorsed the Mania love style, and perhaps the small sample size made potential differences impossible to detect. Future studies using qualitative approaches and case studies may be needed to further understanding of the relationship between these variables. In the meantime, students engaged in Manic love relationships may continue to benefit from interventions grounded in Lee's (1973) initial findings.

On the basis of the significant correlations among the variables, the extensive literature linking social support with positive mental and physical health, and a plethora of studies and models stressing the importance of relationships during the college years, the finding that only $15.8 \%$ of the variance in wellness was predicted by a combination of liking and love styles, as measured by the RLS and the LAS subscales, was surprising. This finding may be partially because of the positive intercorrelations among positive love styles (Eros, Storge, Pragma, and Agape), effectively weakening the influence of each on the Total Wellness factor. Or, it could be that Total Wellness, a holistic construct made up of wide-ranging second- and third-order factors (see Figure 1), is too broad a construct to predict using only social wellness variables. On the other hand, Myers and Sweeney (2005a) underscored the empirical relationships among wellness factors; thus, enhancing relationship wellness should enhance overall wellness. The significant relationships found between liking, the Eros and Mania love styles, and overall wellness suggest that a focus on these 
variables through preventive and developmental counseling interventions could be an important means of enhancing undergraduates' holistic wellness.

\section{Gender and Age Differences in Liking, Love Styles, and Wellness}

It is noteworthy that only three statistically significant gender differences were found in any of the variables studied, with scores for men higher than scores for women in each case. The calculation of Levene's statistic revealed that the variances were equal despite differing sample sizes for female and male participants, supporting the strength of the findings. The findings of higher scores for the Agape subscale and higher scores on Coping Self and Physical Self wellness among the male participants are consistent with those of earlier studies. However, Myers and Mobley (2004) found gender differences in wellness on 10 wellness scales $(p<.001)$, with men scoring higher except on the Essential Self and Love factors. Limitations in the current sample may account for the differing findings in this study. The lack of significant age differences, contrary to earlier findings, is an additional consideration here.

\section{Confirmatory and Contradictory Findings of Ethnic Differences in Love Styles and Wellness}

Ethnic differences in love styles provided the most striking within-group differences in this study. Several studies have shown that Caucasian individuals tend to have more individualistic approaches to relationships with others and place higher value on their own goals over the maintenance of relationships, whereas African American individuals often are more collectivist, placing higher value on the maintenance of relationships (e.g., Gushue \& Constantine, 2003). In the present study, African American students' higher scores on the Pragma subscale suggest that they are more planful when choosing romantic partners than are their Caucasian peers. This is consistent with a more collectivist orientation, in that African American cultures often place a high value on familial opinions and acceptance (Taylor \& Roberts, 1995; Utsey, Adams, \& Bolden, 2000) and might seek partners who seem compatible with the family system. If such a student's desired partner does not fit with expectations of family, internalized conflict may result in a need for counseling. Conversely, higher scores on the Mania subscale among Caucasian students in comparison with African American students suggest a potentially less healthy approach to relationships, perhaps because of a more individualistic attitude focusing on personal desires (Kim, Sherman, Ko, \& Taylor, 2006). These students are likely to present with issues when the object of their affection spurns them.

Consistent with earlier findings (e.g., Myers \& Mobley, 2004; Shurts, 2004), African American students endorsed higher levels of Essential Self wellness than did their Caucasian classmates, whereas Caucasian students endorsed higher levels of Physical Self wellness than did their African American peers. These are important findings for counselors using strengths-based approaches. Such 
findings demonstrate wellness components about which each group feels more confident and competent. Furthermore, lower scores suggest areas of potential improvement by ethnicity (e.g., White students may benefit from exploring their cultural identity, whereas African American students may benefit from interventions designed to improve aspects of nutrition and exercise).

Contrary to the current findings of no differences, Shurts (2004) found higher Coping Self wellness among African American students and Myers and Mobley (2004) found a mixed pattern among the third-order factors. Additional studies are needed to clarify the nature of ethnic differences in wellness in this area as a foundation for counseling practice.

\section{Comparison of Study Participants With Norm Groups}

Comparisons of the current study's participants with the only available norm group revealed differences on several wellness factors, the most salient to this study being the Love scale. The finding of high levels of Love wellness combined with a high preference for romantic love (Eros love style) and a low preference for game-playing love (Ludus love style) suggests healthy levels of loving characteristics for these undergraduate participants. Previous authors (e.g., Lee, 1973) suggested that this age group might be more prone to the negative love styles of Ludus (game-playing or manipulative love) or Mania (obsessive love). On the contrary, the Eros (romantic love) and Storge (friendship love) love styles were the two more preferred styles. This suggests that despite increases in the frequency of casual sex among emerging adults (Feldman, Turner, \& Araujo, 1999; Grello, Welsh, Harper, \& Dickson, 2003), this sample of students did not view love as a "game"; rather, they want a romantic and sensual relationship with a partner they also view as a friend. This could account for the large number of "hook-ups" (casual sexual encounters) between two individuals in a friendship (Grello et al., 2003; Manning, Longmore, \& Giordano, 2000). Whether the geographic restriction of the current sample accounted for these findings is an important consideration that can only be addressed through further studies with more representative samples. Although it is important to acknowledge mean differences, considerable diversity existed in the sample. Thus, students with lower scores on Love wellness or the healthy love styles (i.e., Eros, Storge, Pragma, or Agape) may be particularly at risk regarding their ability to develop healthy intimate relationships. Likewise, students engaging in Ludic or Manic love styles may have particular challenges in developing successful intimate relationships. Similarly, although mean scores for the RLS and Friendship wellness were relatively high, the broad range of scores suggests a need to identify students at risk for relationship problems and develop interventions to help those with lower scores on the RLS or Friendship wellness to develop more effective, positive, and satisfying friendships.

The current sample was small and geographically restricted; hence, findings may have limited generalizability to the population of college students and 
emerging adults in general. The lack of available, current norms for the RLS and LAS as well as the significant differences from Myers and Mobley's (2004) findings are an additional consideration in interpreting the results of the current study. Methodological issues (e.g., ordering effects of the instruments, use of only self-report assessments, lack of information concerning current involvement in romantic relationships) also limit the conclusions that may be drawn. Although caution is always encouraged in making inferences from correlational data, particularly given low to moderate levels of shared variance, the results of this study have implications for counselors working with emerging adults in addressing relationship concerns.

\section{IMPLICATIONS}

Counselors working with undergraduates often encounter students who are struggling with relationship issues. These problems can range from developmentally "normal" aspects of romantic relationship development (e.g., dealing with a breakup, anxiety about the lack of a boyfriend or girlfriend, questioning if or when to engage in sexual activities) to less typical but very serious issues (e.g., date rape, contracting a sexually transmitted disease). Regardless of the severity of the presenting relationship issue(s), holistic wellness is most likely negatively affected (Myers \& Sweeney, 2005a). As such, the current findings have numerous implications for any counselors working with undergraduate populations in the areas of prevention-based practice, developmental interventions, and psychotherapeutic work.

From a preventive perspective, college counselors can offer a variety of psychoeducational groups to help students learn healthy relationship skills. Assessment of liking, loving, and wellness factors can provide a springboard for discussions. Some students may perceive counseling as stigmatizing but view wellness programs as educational in nature; thus, college counselors may find that partnerships with campus wellness programs offer a ready means of outreach to students at risk for relationship problems. The increasing frequency of casual sexual encounters among college students (Feldman et al., 1999; Grello et al., 2003), particularly intoxicated students (Desiderato \& Crawford, 1995), and the increasing rates of undergraduate acquaintance/date rape (Sampson, 2002) suggest that students could benefit from a forum in which they can learn about and discuss relationship safety (both psychological and physical) and wellness (both social and holistic). Such groups may help prevent relationship problems and open avenues for discussion of better ways to resolve existing issues.

By helping students become more self-aware (and other aware) regarding their love style and wellness, counselors can help students become better equipped to succeed romantically. Counselors can help students to understand that each individual brings his or her own love style preference to a relationship and, similarly, each individual's areas of strength and weakness influence the rela- 
tionship. For example, a heterosexual college couple might consist of a woman who is more pragmatic about the relationship than is the man. This could be a source of contention (e.g., she consistently wants to analyze the status of the relationship; he does not). However, if both parties recognize, understand, and respect their different approaches to the romantic relationship, the couple will have a greater chance of success. Helping these two students reach a mutual understanding could be accomplished through individual counseling. Whereas many counselors do not work with couples, the development of strengths-based couples groups or seminars might be an innovative way to explore some of these issues from a strengths-based perspective. Likewise, similar issues could be explored in conjoint couple sessions.

Counselors may explore love style preferences with students who struggle with finding and maintaining healthy romantic relationships. Counselors also can use a focus on wellness to help students develop more successful relationships. For example, a student who is engaged in a pattern of Mania-styled love relationships may benefit from an assessment of wellness factors to identify strengths that can be used to counter negative relationship patterns. A similar assessment would also benefit a student engaging in frequent, unfulfilling casual sexual encounters, a pattern associated with a Ludic love style (Grello, Welsh, $\&$ Harper, 2006). In both cases, operating from a holistic wellness perspective allows the counselor and student to explore areas beyond romantic relationships (e.g., self-efficacy, physical wellness, friendships). Although changing the individual's love style may be difficult, promoting healthier lifestyle choices could provide a tangible focus leading to positive change in other areas of life, including love styles.

Counselors who operate from a strengths-based, wellness approach can develop interventions that emphasize clients' positive assets, including social support. In addition to formal assessments, counselors can make informed guesses about their clients' strengths on the basis of gender, age, and cultural patterns. When a student is having difficulty making romantic connections, the counselor can help coconstruct strategies for meeting people using the client's other wellness component strengths or comfort areas.

\section{CONCLUSION}

The findings of the current study support the hypothesis that liking and love styles are both correlates and predictors of wellness in undergraduates. Having healthy platonic friendships and an absence of the negative Mania love style are predictive of greater wellness. As a consequence, counselors who target strategies for helping students develop and maintain friendships and healthy love relationships may help to enhance overall wellness. The current findings indicate the need for continued attention to the dynamics of relationships among emerging adults, including studies of single and coupled individuals, persons who are 
and are not able to establish effective social networks, and outcome studies to determine what methods are most effective in helping undergraduates develop and sustain relationship skills. It seems that a focus on healthy friendships (platonic love styles) could be beneficial for all in this population.

\section{REFERENCES}

Arnett, J. J. (1998). Learning to stand alone: The contemporary American transition to adulthood in cultural and historical context. Human Development, 41, 295-315.

Arnett, J. J. (2000). Emerging adulthood: A theory of development from the late teens through the twenties. American Psychologist, 55, 469-480.

Bierhoff, H.-W., \& Schmohr, M. (2004). Romantic and marital relationships. In F. R. Lang \& K. L. Fingerman (Eds.), Growing together: Personal relationships across the lifespan (pp. 103-129). New York: Cambridge University Press.

Chickering, A. W., \& Reisser, L. (1993). Education and identity (2nd ed.). San Francisco: Jossey-Bass.

Cohen, J. (1988). Statistical power analysis for the behavioral sciences (2nd ed.). Hillsdale, NJ: Erlbaum.

DeLucia-Waack, J. L., Gerrity, D. A., Taub, D. J., \& Baldo, T. D. (2001). Gender, gender role identity, and type of relationship as predictors of relationship behavior and beliefs in college students. Journal of College Counseling, 4, 32-48.

Desiderato, L. L., \& Crawford, H. J. (1995). Risky sexual behavior in college students: Relationships between number of sexual partners, disclosure of previous risky behavior, and alcohol use. Journal of Youth and Adolescence, 24, 55-68.

Dixon Rayle, A., \& Myers, J. E. (2004). Counseling adolescents toward wellness: The roles of ethnic identity, acculturation, and mattering. Professional School Counseling, 8, 81-90.

Enochs, W. K. (2001). Wellness and adjustment in college freshmen based on type of residence hall and gender. Unpublished doctoral dissertation, University of Arkansas.

Feldman, S. S., Turner, R. A., \& Araujo, K. (1999). Interpersonal context as an influence on sexual timetables of youths: Gender and ethnic effects. Journal of Research on Adolescence, 9, 25-52.

Goldscheider, F., \& Goldscheider, C. (1994). Leaving and returning home in 20th century America. Population Bulletin, 48, 2-35.

Grello, C. M., Welsh, D. P., \& Harper, M. S. (2006). No strings attached: The nature of casual sex in college students. The Journal of Sex Research, 43, 255-267.

Grello, C. M., Welsh, D. P., Harper, M. S., \& Dickson, J. W. (2003). Dating and sexual relationship trajectories and adolescent functioning. Adolescent and Family Health, 3, 103-112.

Guarascio, J. (2005). Relationships among collectivism, gender, and perceptions of love in a college sample. Dissertation Abstracts International, 66 (5), 2876B.

Gushue, G. V., \& Constantine, M. G. (2003). Examining individualism, collectivism, and self-differentiation in African American college women. Journal of Mental Health Counseling, 25, 1-15.

Hattie, J. A., Myers, J. E., \& Sweeney, T. J. (2004). A factor structure of wellness: Theory, assessment, analysis, and practice. Journal of Counseling of Development, 82, 354-364.

Hendrick, C., \& Hendrick, S. S. (1986). A theory and method of love. Journal of Personality and Social Psychology, 50, 392-402.

Hendrick, C., \& Hendrick, S. S. (1989). Research on love: Does it measure up? Journal of Personality and Social Psychology, 56, 784-794.

Hendrick, C., Hendrick, S. S., \& Dicke, A. (1998). The Love Attitudes Scale: Short form. Journal of Social and Personal Relationships, 15, 147-159.

Hermon, D. A., \& Hazler, R. J. (1999). Adherence to a wellness model and perceptions of psychological well-being. Journal of Counseling \& Development, 77, 339-343.

Hettler, B. (1984). Wellness: Encouraging a lifetime pursuit of excellence. Health Values: Achieving High Level Wellness, 8, 13-17.

Kim, H. S., Sherman, D. K., Ko, D., \& Taylor, S. E. (2006). Pursuit of comfort and pursuit of harmony: Culture, relationships, and social support seeking. Personality and Social Psychology Bulletin, 32, 1595-1607.

Lee, J. A. (1973). The colors of love: An exploration of the ways of loving. Don Mills, Ontario, Canada: New Press. 
Lefkowitz, E. S., Gillen, M. M., Shearer, C. L., \& Boone, T. L. (2004). Religiosity, sexual behaviors, and sexual attitudes during emerging adulthood. The Journal of Sex Research, 41, 150-159.

Lin, L.-W., \& Huddleston-Casas, C. A. (2005). Agape love in couple relationships. Marriage \& Family Review, 37, 29-48.

Manning, W. D., Longmore, M. A., \& Giordano, P. C. (2000). The relationship context of contraceptive use at first intercourse. Family Planning Perspectives, 32, 104-110.

Myers, J. E., \& Bechtel, A. (2004). Stress, wellness, and mattering among cadets at West Point: Factors affecting a fit and healthy force. Military Medicine, 169, 475-482.

Myers, J. E., \& Mobley, A. K. (2004). Wellness of undergraduates: Comparisons of traditional and nontraditional students. Journal of College Counseling, 7, 40-49.

Myers, J. E., \& Shurts, W. M. (2002). Measuring positive emotionality: A review of instruments assessing love. Measurement and Evaluation in Counseling and Development, 34, 238-254.

Myers, J. E., \& Sweeney, T. J. (Eds.). (2005a). Counseling for wellness: Theory, research, and practice. Alexandria, VA: American Counseling Association.

Myers, J. E., \& Sweeney, T. J. (2005b). The Five Factor Wellness Inventory. Menlo Park, CA: Mind Garden.

Nava, G. R., \& Bailey, K. G. (1991). Measuring psychological kinship: Scale refinement and validation. Psychological Reports, 68, 215-227.

Neto, F., \& Pinto, M. d. C. (2003). The role of loneliness, gender and love status in adolescents' love styles. International Journal of Adolescence and Youth, 11, 181-191.

Osborn, C. J. (2005). Research on college student wellness. In J. E. Myers \& T. J. Sweeney (Eds.), Counseling for wellness: Theory, research, and practice (pp. 77-88). Alexandria, VA: American Counseling Association.

Rubin, Z. (1970). Measurement of romantic love. Journal of Personality and Social Psychology, 16, 265-273.

Sampson, R. (2002). Acquaintance rape of college students (Problem-Oriented Guides for Police Series, No. 17). Retrieved January 11, 2007, from the U.S. Department of Justice, Office of Community Oriented Policing Services Web site: http://www.cops.usdoj.gov/pdf/e03021472.pdf

Sandler, R. L. (1998). College students' use of psychotherapeutic services as a function of year in school. Dissertation Abstracts International, 59 (4), 1081 A.

Shifren, K., Furnham, A., \& Bauserman, R. L. (2003). Emerging adulthood in American and British samples: Individuals' personality and health risk behaviors. Journal of Adult Development, 10, 75-88.

Shurts, W. M. (2004). The relationships among marital messages received, marital attitudes, relationship self-efficacy, and wellness among never-married traditional-aged undergraduate students. Dissertation Abstracts International, 65 (8), 2910A.

Sinclair, S. L., \& Myers, J. E. (2004). The relationship between objectified body consciousness and wellness in a group of college women. Journal of College Counseling, 7, 150-161.

Sprecher, S., \& Toro-Morn, M. (2002). A study of men and women from different sides of earth to determine if men are from Mars and women are from Venus in their beliefs about love and romantic relationships. Sex Roles, 46, 131-147.

Spurgeon, S. L., \& Myers, J. E. (in press). African American males: Relationships among racial identity, college type, and wellness. Journal of Black Studies.

Taylor, R. D., \& Roberts, D. (1995). Kinship support and maternal and adolescent well-being in economically disadvantaged African-American families. Child Development, 66, 1585-1597.

Utsey, S. O., Adams, E. P., \& Bolden, M. (2000). Development and initial validation of the Africultural Coping Systems Inventory. Journal of Black Psychology, 26, 194-215. 